\title{
REVIEWS
}

Sylwia Hnitecka ${ }^{1, \text { D-F, Kamil Nelke }}$ 2, D-F

\section{Rhinocerebral Mucormycosis: Clinical Outcome, Diagnosis, Treatment - Review of the Literature}

\section{Mukormykoza nosowo-mózgowa: obraz kliniczny, diagnostyka, leczenie - przegląd piśmiennictwa}

${ }^{1}$ Student Research Group, Department of Maxillo-Facial Surgery, Wroclaw Medical University, Wrocław, Poland

${ }^{2}$ Department of Maxillo-Facial Surgery, Wroclaw Medical University, Wrocław, Poland

A - research concept and design; $\mathbf{B}$ - collection and/or assembly of data; $\mathbf{C}$ - data analysis and interpretation;

D - writing the article; $\mathbf{E}$ - critical revision of the article; $\mathbf{F}$ - final approval of article

\begin{abstract}
Many pathogens present in the human environment, in immunocompromised patients, can cause extremely severe opportunistic infections. Most patients suffering from immunological disorders are rarely treated at maxillo-facial departments. In some special cases they require a direct clinical approach. Fungal infections in the cranio-facial area do not occur often, as opposed to infections from bacterial flora which are most frequently found. Some special conditions and requirements are needed to be present for the occurrence of fungal infections. If found, many of them are treated locally by antifungal medicaments, while a few of them require additional radical surgical excisional approach. Mucor sp. is one of these infections and it is related with mucormycosis (zygomycosis). Rhinocerebral zygomycosis is particularly dangerous. This rare cranio-facial infection is a great challenge for all clinicians and surgeons. It seems that only an accurate and proper diagnosis has an impact on the patient's survival and post-treatment quality of life. In this paper we focus on recent clinical findings and treatment methods of this disease (Dent. Med. Probl. 2016, 53, 4, 536-541).
\end{abstract}

Key words: fungal infections, mucormycosis, zygomycosis, rhinocerebral mucormycosis.

Słowa kluczowe: infekcje grzybicze, mukormykoza, zygomykoza, mukormykoza nosowo-mózgowa.

Many pathogens present in the human environment often can cause asymptomatic and selfresolving infection in immunocompetent individuals. Reduced immunity may contribute to very severe opportunistic infections. The risk of certain diseases correlates greatly with a decrease in the level of CD4 immunoglobulin. Opportunistic pathogens include many kinds of protozoa, fungi, bacteria and viruses. Examples could be as follows: Toxoplasma gondii, Cryptosporidium sp., Candida sp., Cryptococcus sp., CMV, VZV, Mycobacterium tuberculosis, Salmonella sp., and other $[1,2]$. A good example is found in HIV/AIDS positive patients. This group of diseases is often related with opportunistic infections such as tuberculosis of the lungs, salmonellosis, candidiasis and others [2]. Some fungal infections have a fulminant course and often lead to death.

Other infections are often observed in the course of other systemic diseases associated with decreased immunity. One of opportunistic infection is mucormycosis (zygomycosis) caused by saprophytic fungi belonging to the class of Zygomycetes, the Mucorales order (e.g., Rhizopus sp., Mucor sp., Absidia sp., Rhizomucor sp., Cunninghamella $s p$.). These organisms are mainly found in the soil, decaying organic matter and necrotic tissues. Risk factors for the development of mu- 
cormycosis include: diabetes, ketoacidosis, AIDS, leukemia, lymphoma, anti-metabolites therapy, steroid therapy, severe burns, neutropenia, malnutrition, iron overload, organs or bone marrow transplantation and probably other rare diseases [1-4]. A common way of transmission is inhalation of spores or direct contact by damaged skin or mucous surfaces. Treatment of mucormycosis is a great challenge and it is often life-threatening [1-6]. In this article the authors present the current guidelines, treatment strategies, diagnosis and quality of life of patients with craniofacial mucormycosis.

\section{Incidence and Prevalence}

Mignogna's et al. [7] statistical analysis from the year 2010 showed that the occurrence of mucormycosis in the USA is estimated at 500 new cases each year. The most common form is the rhinocerebral one $[3,8-10]$ and it is found in $44-49 \%$ of all detected zygomycosis. Retrospective analysis of 98 cases made by Vaezi et al. [11] showed that rhinocerebral form, characterized by the highest mortality rate was detected most frequently in the gathered data (about $48.9 \%$ of all clinical subtypes of rhinocerebral zygomycosis). For comparison: the sinonasal $-7.1 \%$ and sinonasaloorbital $-6.1 \%$ forms were not often found. This disease may occur in all patients regardless of age and gender $[9,12]$. Often the most vulnerable age group were young adults with varying degrees of deficiency of the immune system and also those treated for other systemic diseases.

\section{Epidemiology}

In most cases, severe chronic diseases are mainly responsible for this fungal infection occurrence. Diabetes mellitus, malignancies, severe injuries and transplantations were most frequently mentioned as predisposing factors in world literature. Uncontrolled diabetes and trauma dominate in developing countries, while in highly developed countries, diabetes and cancer seem to be most often related to any forms of fungal infection [12]. Roden's et al. [13] research showed that the most frequently predisposing factor is diabetes, present in $36 \%$ cases, while others are $17 \%$ forms of various malignancies, while $95 \%$ of them are hematological tumors. Almost every fifth person had no disease when infection occurred. At least $25 \%$ is a group with severe trauma [13]. Vaezi et al. [11] also indicates that diabetes is the most common predisposing factor (47.9\%), while the second one are organ or bone marrow diseases $-22.4 \%$. Different statistics were presented by ECMM study group. According to their analysis, a total of $44 \%$ people suffering from mucormycosis had a hematologic malignancy and $15 \%$ had severe trauma [14]. Diabetes is still an important risk factor. The incidence of diabetes in Poland remains on a very high level, and is estimated at $9.03 \%$, according to the 2013 edition of the report "Diabetes. Hidden Pandemic. Situation in Poland". The most common infections in diabetes mellitus are mentioning respiratory infections and urinary tract infections, while mucormycosis is a rare [15].

Mortality rate of mucormycosis is very high, estimated at $40.8-50 \%[11,16]$, while some fungal forms are associated with even a one hundred percent mortality rate [13]. The very high risk of death is related with the rhinocerebral form estimated at even $62.5 \%$ [7]. This is mainly due to a late proper diagnosis, consequently delayed treatment resulting from a misdiagnosis and also to angioinvasion and subsequent tissue necrosis caused by fungi [16]. Patients with diabetes as the only existing disease have a better prognosis than those with other factors related to a decreased immune response, such as malignancy, immunosuppressive therapy or AIDS [17]. The mortality rate among diabetic patients demonstrated by Roden et al. [13] in their research was relatively low compared to patients with other risk factors. The main value was estimated at $44 \%$, while the bone marrow recipient's mortality rate was observed at $91 \%$, patients with renal insufficiency $89 \%$, and systemic lupus erythematosus as $89 \%$. The prognosis for recovery of mucormycosis in diabetes patients is relatively good compared to HIV positive patients, where the mortality rate is $41 \%$ while in organ transplant recipients it is $48 \%$. The most common known way of infection is inhaling spores [7]. Most studies indicate that almost $2 / 3$ of known mucormycosis cases involve men [14] and there is no detailed current research to explain this predisposition. Advanced infection may result in Lemierre syndrome and death [8]. Almost $75 \%$ of zygomycosis cases are caused by Rhizopus sp. and Mucor sp. (13\%). The highest mortality rate is recorded through the Cunninghamella bertholletiae infection; however, the pathogen is rarely responsible for mucormycosis, mostly because it is found only in $6 \%$ of all infections. The overall survival rate is high, estimated at about $85 \%$ and higher in the nasocerebral, pulmonary or disseminated forms, because it is more often diagnosed at an early stage. Also, a very important key factor is the presence of diabetic ketoacidosis, which is relatively easy to treat $[7,15,18]$. 


\section{Clinical Types}

There are five main clinical forms of zygomycosis: rhinocerebral, pulmonary, gastro-intestinal, cutaneous and disseminated. Rhinocerebral type involves the nasal cavity, paranasal sinuses, orbital and intracranial structures. A further division of this clinical form is based on the location of the fungus and is as follows: rhinocerebral, rhinoorbital and rhinomaxillaris forms [3]. The sinonasal subtype is very important, because the troublesome location and difficult, late-occurring visible signs detected in late advanced clinical stages can frequently decide the fate of the patient (Table 1).

Patients often start treatment of other conditions because of non-specific clinical signs of mucormycosis. Most of them (79\%) have a slightly increased temperature [19]. Initial symptoms of this disease usually suggest sinusitis. Patients quite often present with pain, swelling of the face, orbits, headache, runny nose, hyposmia, blurred vision and periorbital cellulitis $[3,4,8,20]$. Ambiguous signs of facial swelling, nasal congestion and nasal secretion are often present in the course of other infections, such as allergy, inflammations, thus delaying of the proper diagnosis of mucormycosis.

More characteristic signs appear later with the development of the disease. They include palate and nasal cavity lesions-eschars, necrotic ulcers (usually black color), called "the black eschars". Intraoral exams reveal a tilted occlusion which is associated with the deformation of the maxilla due to the disease development and infiltration of the hard and soft tissues. Mucormycosis often leads to the destruction of the maxilla, mandible, tongue, lips and cheeks [3, 21-23]. Ptosis, pupil dilatation, ipsilateral face paresthesis indicate the involvement of the branches of the trigeminal and facial nerves. Kursun et al. [19] point out that the orbital apex syndrome as one of atypical clinical symptoms, which may be caused by e.g., bacterial infections, tumors or sarcoidosis. This is due to the infection of the cranial nerves: II, III, IV, $V_{1}$, VI. In the second clinical stage of mucormycosis patients can lose vision due to retinal vascular invasion. During the third stage, other additional symptoms are also found - loss of consciousness, coma - due to CNS structures disorders and also cranial nerve palsy, obturation of the brain vessels or blood clots in the cavernous sinus $[3,6]$.

Early, proper diagnosis of the disease, which is a great challenge, is a key point of accurate treatment. Mucormycosis differential diagnosis includes: necrotizing fasciitis, aspergillosis, actinomycosis, syphilis, malignancies, tuberculosis, Wegener's granuloma, midline lethal granuloma, Herpes simplex infection and Herpes zoster infection. Other pathogens, whose infection is associated with angioinvasion are: Fusarium sp., Scedosporium sp. and Pseudomonas aeruginosa. It is important to determine whether there are any risk factors or underlying diseases. Histological findings may be atypical, especially if antifungal therapy was scheduled before collecting some samples or scrubs. Moreover, the lack of specific symptoms and biomarkers, and a high risk of damage to the material during collection and processing, are factors impeding definitive diagnosis $[3,5,12,24]$. In the case of rhinoorbital mucormycosis, any material for microscopic examination is taken mostly from nose secretions, the nasal cavity and a biopsy of the infected tissue [16] (Table 2).

$\mathrm{CT}$ and MR findings are not specific enough. $\mathrm{CT}$ is not appropriate for detecting any signs of early changes. Invasive mucormycosis of the sinuses may be often invisible. MR is significantly more accurate $[3,16]$. Molecular techniques are very useful in order to determine the exact etiology of the disease, but should never be used as an only method of an examination [19]. Currently, there are also studies of specific T-cell for $M u$ cor sp., focused in the differential diagnosis with aspergillosis. Presented results are helpful to exclude this type of infection, obtaining a negative test result of galacto-mannan and B-D glucan. In modern laboratory tests there are also methods with usage of the spectrograph MALDI-TOF to identify those species [18] (Table 3).

\section{Treatment}

Appropriate mucormycosis treatment involves simultaneous antifungal pharmacotherapy, surgical debridement of infected tissue and

Table 1. Clinical stages of rhinocerebral mucormycosis depend on the location of the fungus, based on Jatinder's article and own clinical description [3]

\begin{tabular}{|l|l|}
\hline Stage 1 & $\begin{array}{l}\text { Infection of the nasal cavity mucosa, sinuses, local vascular thrombosis. This leads to rapid spread } \\
\text { of disease to soft tissues (face skin, oral cavity mucosa). Infection may pass through the cartilage } \\
\text { and bone barrier }\end{array}$ \\
\hline Stage 2 & \begin{tabular}{l} 
Infection of orbits and retinal vessels \\
\hline Stage 3
\end{tabular} \\
$\begin{array}{l}\text { Intracranial invasion (through the orbital apex, cribriform plate of ethmoid bone and ethmoidal } \\
\text { fovea) }\end{array}$ \\
\hline
\end{tabular}


Table 2. The possible diagnostic methods and their effectiveness. Own clinical description based on articles $[3,18,19,21,25,26]$

\begin{tabular}{|c|c|c|}
\hline $\begin{array}{l}\text { Radiological } \\
\text { imaging }\end{array}$ & CT, MRI & $\begin{array}{l}\text { In the CT image are visible changes in the bone (sinuses bone walls de- } \\
\text { struction), inverted "halo" mucosal thickening, swelling of soft tissue and } \\
\text { extraocular muscles, exophthalmia. MRI reveals early changes in the soft } \\
\text { tissues, intracranial lesions, involvement of the cavernous sinus, early vas- } \\
\text { cular invasion }\end{array}$ \\
\hline $\begin{array}{l}\text { Microbiological } \\
\text { culture }\end{array}$ & $\begin{array}{l}\text { fungus culture from } \\
\text { biopsy }\end{array}$ & $\begin{array}{l}\text { Often it gives a false negative result due to the material being damaged } \\
\text { during the process of obtaining it. A biopsy should be obtained from the } \\
\text { depth of infected tissues. Microbiological culture is currently at the level } \\
\text { of } 50-71 \% \text { of efficiency and shows an upward trend }\end{array}$ \\
\hline Histopathology & $\begin{array}{l}\text { staining: } \mathrm{H}+\mathrm{E} \text {, Gomori- } \\
\text {-Grocott, PAS }\end{array}$ & $\begin{array}{l}\text { Tissue necrosis, angioinvasion with obstruction and the presence of cha- } \\
\text { racteristic broad, non-septate hyphae with branching at right-angle }\end{array}$ \\
\hline $\begin{array}{l}\text { Moleculat } \\
\text { techniques }\end{array}$ & $\begin{array}{l}\text { e.g.: PCR, RFLP, DNA- } \\
\text {-sequencing, PCR-product } \\
\text { melting curve }\end{array}$ & Analysis of the pathogen's genetic material \\
\hline
\end{tabular}

Table 3. Differential diagnosis with other fungi species description. Own clinical description based on articles $[18,27]$

\begin{tabular}{|l|l|}
\hline Aspergillosis & $\begin{array}{l}\text { The final diagnosis of aspergillosis and mucormycosis is troublesome, however histology eva- } \\
\text { luation leads to final proper diagnosis. Hyphae of these fungi are very characteristic. Hyphae } \\
\text { of } \text { Mucor sp. are large, wide, non-septate with a branching at right angles, while Aspergillus sp. } \\
\text { hyphae are interspersed with the branching angle at } 45^{\circ}\end{array}$ \\
\hline $\begin{array}{l}\text { Aspergillosis, fusariosis, } \\
\text { candidiasis }\end{array}$ & $\begin{array}{l}\text { The differential diagnosis of these three species may include detection of the } 1,3-\beta \text {-D-glucan } \\
\text { because Mucor sp., which one gives only negative result }\end{array}$ \\
\hline
\end{tabular}

the elimination of the underlying diseases which are important factors predisposing the patient to various forms of zygomycosis. The range of resection is often very large, making it sometimes necessary to perform maxillectomy, mandibulectomy or even orbital exenteration. The surgical procedure, though it is the only treatment option, is often not sufficient enough $[3,16]$. The surgical treatment of patients with neutropenia may increase the mortality rate [28]. Orbital exenteration is not performed in all patients with orbital involvement [16]. This procedure should be performed when retinal artery embolism, orbital apex necrosis or the invasion within the eyeball are preset both clinically and radiologically [29]. Patients in the early stages of rhinocerebral mucormycosis may be considered for endoscopic surgery [16]. However, sometimes the full exposure and visual assessment of the operative field can be a better method than less radical endoscopic procedure.

After extensive resection it is possible to perform some types of reconstructive surgery. Surgeons use eg. alloplastic implants (e.g., titanium mesh) or free flaps [3]. Before the start of the surgical rehabilitation it is necessary to confirm the absence of infection, and to make sure that the other tissues are healthy [23]. Patients eligible for the various stages of reconstruction could be qual- ified, depending on the severity and clinical form of mucormycosis. During preparation for surgery, each patient should be circulatory and respiratory efficient with stable chronic disease.

Amphotericin B is the basic drug in treatment of mucormycosis (survival rate up to $72 \%$ ). This drug may be used in various pharmacological forms. Most common one is the conventional intraoral drug, however other appliance forms are used; such as - liposome, lipid complex or dispersed colloidal solution. Fungistatic action and high nephrotoxicity are the main drawbacks of this drug $[3,28]$. Systemic administration of the medicament slows infections and allows the control of the disease within the tissue, which cannot be resected [25]. Lipid forms are associated with lower risk of side effects (nephrotoxicity) and longer remaining in the circulatory system, so there is high concentration of the drug within infected tissues. Therapeutic effect is equal for conventional and lipid amphotericin $B$, so lipid form should be used only for patients with renal impairment $[3,16,25]$.

The total dose of conventional amphotericin B estimated at 3-4 g should be given within 6-12 weeks. The daily dose of intravenous dose is usually $1 \mathrm{mg} / \mathrm{kg}$. The lipid form is administered by infusion at a dose of $5 \mathrm{mg} / \mathrm{kg} / \mathrm{day}$. Posaconazole may be given together with am- 
photericin B (total dose $800 \mathrm{mg} /$ day in 2-4 doses), especially in cases of resistant zygomycosis, intoleration of amphotericin B. It is also important to increase patients immunity and treat any co-existig metabolic diseases $[3,23]$. Additional supportive therapy treatment options are deferasirox, hyperbaric oxygen (stimulation of neovascularization, thus improving perfusion of the tissues), transfusion of leukocytes, interferon alpha, immunoglobulin polyvalent and GM-CSF (granulocyte-macrophage colony-stimulating factor), G-CSF (granulocyte colony-stimulating factor) $[3,4,16,23]$. ECMM research has shown that mortality rate during the use of both antifungal drugs and surgical intervention is estimated at $24 \%$, while the operation itself is at $44 \%$, while and pharmacological treatment itself is up to $58 \%$ [14].

Innovative treatment method described by Ogawa et al. [29] proved to be effective. It based on the combination of liposomal amphotericin $B(10 \mathrm{mg} / \mathrm{kg} /$ day $)$ with micafungin $(6 \mathrm{mg} / \mathrm{kg} /$ day) with simultaneous daily irrigation of maxillary sinuses with solution of amphotericin B. Also a combination of amphotericin $B$ and caspofungin seems to be promising [30]. Association with approved in 2015 isavuconazole can also be effective, but it requires more clinical studies [31].

\section{Conclusion}

Mucormycosis as an opportunistic, life threatening fungal infection is a great challenge for every clinician and especially surgeons. The rapid progress of this disease, extensive involvement of cranio-facial structures requires certain early diagnosis and treatment, which includes antifungal pharmacotherapy (lipid forms of amphotericin B are usually used at first), radical surgical debridement and correction of underlying diseases, like ketoacidosis in diabetes mellitus. The major characteristics of this disease are necrosis and thrombosis because of fungal angioinvasion. Very characteristic "black eschars" on the palate are visible. Diagnosis includes radiological imaging, microbiological culture wraps, molecular techniques, but most importantly histological evaluation. Detection of broad, non-septate branched at right-angles hyphae confirm a suspicion of mucormycosis. CT is a less effective method for the diagnosis of this disease. MRI is very sensitive diagnostic method that should be used especially in case of any changes at the early stages of zygomycosis. It is possible that routine immunocompromised patients check-ups treated for systemic diseases could contribute to more rapid detection of possible co-infections and lesions emerging in the course of these diseases.

\section{References}

[1] WesoŁowska M., Gąsiorowski J., Jankowski S.: The opportunistic protozoa in immunocompromised individuals. Adv. Clin. Exp. Med. 2005, 14, 349-355 [in Polish].

[2] Holmes C.B., Losina E., Walensky R.P., Yazdanpanah Y., Freedberg K.A.: Review of human immunodeficiency virus type 1 - related opportunistic infections in Sub-Saharan Africa. Clin. Infect. Dis. 2003, 36, 652-662.

[3] Jatinder N.K., Srivalli N., Jyotsna G.: Rhinocerebral mucormycosis - an emerging threat. J. Oral Maxillofac. Surg. Med. Pathol. 2015, 27, 550-557.

[4] Pajpani M., Webb R.: Lingual necrosis caused by mucormycosis in a patient with aplastic anaemia: Case report. Br. J. Oral Maxillofac. Surg. 2014, 52, 144-146.

[5] Lador N., Polacheck I., Gural A., Sanatski E., Garfunkel A.: A trifungal infection of the mandible: Case report and literature review. Oral Surg. Oral Med. Oral Pathol. Oral Radiol. Endod. 2006, 101, 451-456.

[6] Zвоrowsкa-Sкrobaneк J., Misiuk-HojŁo M.: Orbital infections - interdisciplinary problem of ophthalmologists, laryngologists and maxillofacial surgeons. Dent. Med. Probl. 2007, 44, 373-376 [in Polish].

[7] Mignogna M.D., Fortuna G., Leuci S., Adamo D., Ruoppo E., Siano M., Mariani U.: Mucormycosis in immunocompetent patients: A case-series of patients with maxillary sinus involvement and a critical review of the literature. Int. J. Infect. Dis. 2011, 15, 533-540.

[8] Fogarty C., Regennitter F., Viozzi C.F.: Invasive fungal infection of the maxilla following dental extractions in a patient with chronic obstructive pulmonary disease. J. Can. Dent. Assoc. 2006, 72, 149-152.

[9] Bonifaz A., Macias B., Paredes-Farrera F., Arias P., Ponce R.M., Araiza J.: Palatal zygomycosis: Experience of 21 cases. Oral Dis. 2008, 14, 569-574.

[10] Selvamani M., Donoghue M., Bharani S., Madhushankari G.S.: Mucormycosis causing maxillary osteomyelitis. J. Nat. Sc. Biol. Med. 2015, 6, 456-459.

[11] Vaezi A., Moazeni M., Rahimi M.T., de Hoog S., Badali H.: Mucormycosis in Iran: A systematic review. Mycoses, 2016, 59, 402-415.

[12] Katragkou A., Walsh T.J., Roilides E.: Why is mucormycosis more difficult to cure than more common mycoses? Clin. Microbiol. Infect. 2014, 20, 74-81.

[13] Roden M.M., Zaoutis T.E., Buchanan W.L., Knudsen T.A., Sarkisova T.A., Schaufele R.L., Sein M., Sein T., Chiou C.C., Chu J.H., Kontoyiannis D.P., Walsh T.J.: Epidemiology and outcome of zygomycosis: A review of 929 reported cases. Clin. Infect. Dis. 2005, 41, 634-653. 
[14] Skiada A., Pagano L., Groll A., Zimmerli S., Dupont B., Lagrou K., Lass-Florl C., Bouza E., Klimko N., Gaustad P., Richardson M., Hamal P., Akova M., Meis J.F., Rodriguez-Tudela J.L., Roilides E., Mitrousia-Ziouva A., Petrikkos G.: Zygomycosis in Europe: Analysis of 230 cases accrued by the registry of the European Confederation of Medical Mycology (ECMM) Working Group on zygomycosis between 2005 and 2007. Clin. Microbiol. Infect. 2011, 17, 1859-1867.

[15] Casqueiro J., Casqueiro J., Alves C.: Infections in patients with diabetes mellitus: A review of pathogenesis. Indian J. Endocrinol. Metab. 2012, 16, 27-36.

[16] González Ballester D., González-García R., Moreno García C., Ruiz-Laza L., Monje Gil F.: Mucormycosis of the head and neck: Report of five cases with different presentations. J. Craniomaxillofacial Surg. 2012, 40, 584-591.

[17] Trief D., Gray S.T., Jakobiec F.A., Durand M.L., Fay A., Freitag S.K., Lee N.G., Lefebvre D.R., Holbrook E., Bleier B., Sadow P., Rashid A., Chhabra N., Yoon M.K.: Invasive fungal disease of the sinus and orbit: A comparison between mucormycosis and Aspergillus. Br. J. Ophthalmol. 2016, 100, 184-188.

[18] Dzierżanowska D., Gil L., Jakubas B., Kyrcz-Krzemień S., Styczyński J.: Epidemiology and microbiologic diagnostics of invasive fungal disease. Post. Nauk. Med. 2015, 28, 6, 403-409.

[19] Kursun E., Turunc T., Demiroglu Y.Z., Alişkan H.E., Arslan A.H.: Evaluation of 28 cases of mucormycosis. Mycoses, 2015, 58, 82-87.

[20] Mantadakis E., Samonis G.: Clinical presentation of zygomycosis. Clin. Microbiol. Infect. 2009, 15, 15-20.

[21] Samaranayake L.P., Keung Leung W., Jin L.: Oral mucosal fungal infections. Periodontol. 2000, 2009, 49, 39-59.

[22] Hanson K.E., Caligiuri P., Wiggins R.H., Quigley E.P., Kendall B.: Radiologic imaging techniques for the diagnosis and management of invasive fungal disease. Curr. Fung. Infect. Rep. 2015, 9, 180-189.

[23] Metzen D., Böhm H., Zimmermann M., Reuther T., Kübler A.C., Müller-Richter U.D.A.: Mucormycosis of the head and neck. J. Craniomaxillofac. Surg. 2012, 40, 321-327.

[24] Vijayabala G.S., Annigeri R.G., Sudarshan R.: Mucormycosis in a diabetic ketoacidosis patient. Asian Pac. J. Trop. Biomed. 2013, 3, 830-833.

[25] Leitner C., Hoffmann J., Zerfowski M., Reinert S.: Mucormycosis: Necrotizing soft tissue lesion of the face. J. Oral Maxillofac. Surg. 2003, 61, 1354-1358.

[26] Prabhu R.M., Patel R.: Mucormycosis and entomophthoramycosis: A review of the clinical manifestations, diagnosis and treatment. Clin. Microbiol. Infect. 2004, 10 (Suppl. 1), 31-47.

[27] Arndt S., Aschendorff A., Echternach M., Daemmrich T.D., Maier W.: Rhino-orbital-cerebral mucormycosis and aspergillosis: Differential diagnosis and treatment. Eur. Arch. Otorhinolaryngol. 2009, 266, 71-76.

[28] Kunnatowski P.: Pharmacological treatment of fungal sinusitis. Otorynolaryngol. 2010, 9, 13-17.

[29] Ogawa T., Takezawa K., Tojima I., Shibayama M., Kouzaki H., Ishida M., Okabe H., Shimizu T.: Successful treatment of rhino-orbital mucormycosis by a new combination therapy with liposomal amphotericin B and micafungin. Auris Nasus Larynx, 2012, 39, 224-228.

[30] Reed C., Bryan R., Ibrahim A.S., Edwards J., Filler S.G., Goldberg R., Spellberg B.: Combination polyenecaspofungin treatment of rhino-orbital-cerebral mucormycosis. Clin. Infect. Dis. 2008, 47, 364-371.

[31] Walker R.C., Zeuli J.D., Temesgen Z.: Isavuconazonium sulfate for the treatment of fungal infection. Drugs Today, 2016, 52, 7-16.

\section{Address for correspondence:}

Sylwia Hnitecka

Kwiatowa 4

55-020 Stary Śleszów

Poland

E-mail: sylwia.hn94@gmail.com

Conflict of Interest: None declared

Received: 22.04.2016

Revised: 24.06.2016

Accepted: 10.07.2016 